\title{
Container ships: fire-related risks
}

\section{Callesen, Frey Gerner; Blinkenberg-Thrane, Maurice; Taylor, John Robert; Kozin, Igor}

\section{Published in:}

Journal of Marine Engineering and Technology

Link to article, DOI:

$10.1080 / 20464177.2019 .1571672$

Publication date:

2021

Document Version

Peer reviewed version

Link back to DTU Orbit

Citation (APA):

Callesen, F. G., Blinkenberg-Thrane, M., Taylor, J. R., \& Kozin, I. (2021). Container ships: fire-related risks.

Journal of Marine Engineering and Technology, 20(4), 262-277. https://doi.org/10.1080/20464177.2019.1571672

\section{General rights}

Copyright and moral rights for the publications made accessible in the public portal are retained by the authors and/or other copyright owners and it is a condition of accessing publications that users recognise and abide by the legal requirements associated with these rights.

- Users may download and print one copy of any publication from the public portal for the purpose of private study or research.

- You may not further distribute the material or use it for any profit-making activity or commercial gain

- You may freely distribute the URL identifying the publication in the public portal

If you believe that this document breaches copyright please contact us providing details, and we will remove access to the work immediately and investigate your claim 


\section{Container ships: fire related risks}

Frey Gerner Callesen, Maurice Blinkenberg-Thrane, John Robert Taylor \& Igor Kozine (ORCID 0000-0002-9698-7211)

Department of Management Engineering, Technical University of Denmark, Kgs.

Lyngby, Denmark

Corresponding author: I. Kozine, Produktionstorvet 424, 2800 Kgs. Lyngby, Denmark, igko@dtu.dk

Published online: 28 Jan 2019 in Journal of Marine Engineering \& Technology, Taylor \& Francis. https://doi.org/10.1080/20464177.2019.1571672 


\section{Container ships: fire related risks}

The paper describes a study on fire accidents taking place aboard container ships. In total, 39 confirmed container ship fire accidents were discovered in the period 1996-2017. An epidemiological hazard analysis disclosed four high-consequence hazardous cargos that are calcium hypochlorite, compressed charcoal briquette products, rechargeable batteries and divinylbenzene. Cause-consequence analyses of the fire accidents with the four types of cargos were carried out that explicated all possible scenarios of accident escalation starting from a cause and ending with a consequence. The frequency of experiencing major fires was estimated as well. Further, different solutions to reduce fire detection time were explored and supported by fire simulation modelling with computational fluid dynamic software. Results of the simulation for two different detection solutions are presented.

Keywords: container ship; fire; hazard; cause-consequence analysis

\section{Introduction}

The study performed and briefly described in this paper pursued two objectives:

1. reveal and understand the causes and escalation scenarios of fires on container ships from a safety engineering point of view, and

2. provide a basis for evaluating solutions to preventing fires or stopping their escalation.

The results of the accidents' analysis and the demonstrated way of building escalation scenarios should be of interest to the authorities, ship owners, port operators and the chief personnel of the ship crew.

Liner shipping is a global trading industry, which in 2015 was estimated to be responsible for transporting approximately 8.428 billion ton-miles of the world's seaborne trade via containers. The industry's vast size, great market share and high importance for international trade has resulted in an industry competing on capacity, 
economics and efficiency. As a consequence of these competitive factors, an exponential growth in container ship sizes and their cargo carrying capacities have been witnessed throughout the last five decades. Table 1 displays some numbers on the growth rate in the container ships cargo-carrying capabilities (Allianz 2015). TEU in the table stands for Twenty-Foot Equivalent Unit.

Reports and statistics we have collected on major cargo related fires indicate that the crew on-board container ships is left with limited possibilities of detecting and fighting fires, and that there is a need for the improvement of firefighting systems. Also as the throughput of containers in port terminals has increased, the feasibility of physically investigating the content of each container is not possible any longer. Thus, the probability of unknowingly transporting and handling undeclared dangerous goods has increased too. Experts call for better firefighting systems on container ships (MAREX 2017).

Table 1. Container ship capacity growth from 1968 to 2018

\begin{tabular}{|c|c|}
\hline Year & Container ship capacity (TEU) \\
\hline 1968 & 1,530 \\
\hline 1980 & 4,100 \\
\hline 1998 & 8,000 \\
\hline 2012 & 16,000 \\
\hline 2018 & 22,000 \\
\hline
\end{tabular}

Along with the growth of container ships cargo carrying capacity, a number of large fire-related accidents have taken place. A comprehensive search we have carried out returned descriptions of 39 major cargo related fires taking place during the period of 1996 to 2017. These are listed in Appendix and served as the basis for the study.

The incurred losses caused by the listed fires are not known in all cases. However, no total loss of a container ship has taken place during the analysed period. To have an idea of the scale of possible monetary expenditures connected to the 
accidents Table 2 exemplifies a total loss of 19,000 TEU container ship. The figures in the table are based on a study described in (Allianz 2016).

Table 2. Expenditures in case of a total loss a 19,000 TEU container ship (80\% laden)

\begin{tabular}{|l|l|}
\hline Description & Estimated expenditures \\
\hline Hull loss & (Insured value) \$200 million \\
\hline Cargo loss & Approx. \$532 million \\
\hline Removal of wreck and liabilities & Approx. \$300 million \\
\hline Total loss & Approx. \$1 billion \\
\hline
\end{tabular}

One of the main concerns, seen from a safety engineering point of view, is that today's ultra large container ships (ULCS) are built with the same basic design principles as the older smaller container ships, without accounting for possible consequences that could impact safety. From examination of the accident reports retrieved from the European Maritime Safety Agency Database, and such sources as (Murdoch and Tozer, 2012), (BSU 2006, 2014), (DMAIB 2016) and (BEAmer 2017), it seems to have been assumed that safety principles invented and applied decades ago for ships of much smaller capacity and sizes will work with the same efficiency and effectiveness on today's significantly larger ships. The principles that concern the fire safety and fire safety arrangements is the main focus of this study.

Currently, there are no requirements for the installation of fixed fire detection systems above the weather deck of a container ship. "The detection of a fire on deck is left to chance. SOLAS ${ }^{1}$ does not stipulate that fire detectors must be fitted on deck. A fire is only discovered if a perceptible amount of smoke is produced, the fire results in sounds that drown out the ordinary noises of the ship, or if flame is discernible”, says H. Hammer the International Union of Marine Insurance Political Forum Chair. (MAREX 2017).

\footnotetext{
${ }^{1}$ International Convention for Safety of Life at Sea
} 
Thus, the ship’s fire safety above the weather deck relies primarily on visual detection by the crew. The reliability of this method is dependent on the overview/visibility of the containerised cargo from the bridge, weather conditions, location of the container in question (i.e. line of sight to the affected container), general crew rounds, container inspections during voyage and series of other environmental and managerial factors. Due to the increased capacity of the ULCS and the tight stowage of containers, the overview of the containerised cargo is restricted, which may impair the efficiency of this method for detecting fires. Furthermore, this method of detection puts a high responsibility on the crew and simultaneously increases the workload of the individual crew members. The general tendency of reducing manning aboard a ship aggravates this problem.

The range of possible improvements in design principles is not clear. The accident reports, which we have studied, show that improvements in detection are certainly needed, especially for early detection of in-container fires, since firefighting is much simpler in the case of early detection; also, improvements are needed in fighting methods, each improvement requires justification. It is hoped that the current analysis can help to provide a basis for cost benefit analysis. One of the most promising measures is to provide a computerised registration system for individual customers and customer cargo type so that, for example, hazardous cargoes can be transported above deck, and preferable segregated for rapid fire fighting response. 


\section{Hazards and accident scenarios}

A short summary of the data collected on the causes of major ${ }^{2}$ cargo container fires is presented in Table 3. A more detailed table containing the year of the incident and ships' name, along with the cause of the fire can be found in Appendix. The collected data allows for simple epidemiological hazard identification with an indication of the frequencies of fire causes. Several of these cases were found in the European Maritime Safety Agency database, and in the publication by Murdoch and Tozer (2012).

Table 3. Short summary of cargoes that have caused major fire incidents

\begin{tabular}{|l|c|}
\hline Cause of fire accident & $\begin{array}{l}\text { Number of } \\
\text { accidents }\end{array}$ \\
\hline Calcium hypochlorite & 13 \\
\hline Charcoal & 7 \\
\hline Batteries & 2 \\
\hline Pentane and isopentane & 1 \\
\hline $\begin{array}{l}\text { Petroleum based cleaning } \\
\text { fluid }\end{array}$ & 1 \\
\hline PRS-80 \& NA-125 & 1 \\
\hline Thiourea Dioxide & 1 \\
\hline Methyl ethyl ketone & 1 \\
\hline Divinylbenzene & 1 \\
\hline Textiles & 1 \\
\hline Sodium hydroxide & 1 \\
\hline Fertilizer & 1 \\
\hline Cardboard bales & 1 \\
\hline Not known & 7 \\
\hline Total & $\mathbf{3 9}$ \\
\hline
\end{tabular}

As seen from Table 3, at least three causes repeat over the time-span of the collected data: these are the shipment of calcium hypochlorite, charcoal and batteries. Thus, these three hazardous cargos have become subject to scrutiny in the study. Further, the fire accident that took place on MSC Flaminia in 2012 (BSU 2014) has also been

\footnotetext{
${ }^{2}$ A major cargo container fire is defined as an event which causes a disruption in the ships' normal trading pattern, e.g. the ship has to call a port earlier than planned to receive external support or the ship has to visit a shipyard to have repairs performed
} 
thoroughly studied due to its severity and the fact that divinylbenzene is representative of a spectrum of chemicals that may polymerise violently if handled improperly. Below we provide a brief summary of representative cases involving the above described materials:

- 2003 - MV Sea Elegance - Calcium hypochlorite, $\mathrm{Ca}(\mathrm{ClO})_{2}$, will be denoted as CHIO (SAMSA 2005). MV Sea Elegance is a $171 \mathrm{~m}$ long container ship, sailing under Singaporean flag. On October 11th, 2003, during voyage from Port Louis (Republic of Mauritius) to Durban (South Africa), an explosion occurred. It originated from cargo hold number 6, just aft of the accommodation. The fire supposedly originated from a container stored below deck containing $20 \mathrm{t}$ of CHIO. The cargo was stored below deck, as it had not been declared a dangerous good. Remaining containers in the cargo hold carried plastic, rubber and paper goods. Ambient temperatures in cargo hold were $35^{\circ} \mathrm{C}$ on average, and the container itself had been placed up against the heavy fuel oil (HFO) storage tanks, which also provides heat.

- 2015 - Caroline Maersk - Charcoal (DMAIB 2016). Caroline MAERSK is a $347 \mathrm{~m}$ long container ship, sailing under Danish flag. The ship crew comprised a total of 22 persons, with varying nationalities. On August 26th, 2015, during voyage from Chiwan (China) to Tanjung Pelepas (Malaysia), approximately 50 nm from the coast of Vietnam, a fire was discovered in cargo hold 9 positioned close to the amidships section of the ship. The fire was detected through a smoke alarm signal which indicated smoke in the respective hold. As initial response, the ship speed was reduced and the course of the ship was altered to re-direct the smoke from the deck. The ventilation to the hold was terminated and all electrical power switched off. The cargo which initiated the container fire was 
later identified as shisha charcoal. The container had been shipped from a manufacturer in China and loaded on to the ship in Busan (South Korea) 10 days before the fire broke out. The cause of ignition was allegedly due to self-heating of the charcoal.

- 2016 - CMA CGM Rossini - Lithium-ion batteries (BEAmer 2017). CMA CGM Rossini is a $277 \mathrm{~m}$ long container ship, sailing under French flag. The ship’s crew comprises a total of 29 persons with undefined nationalities. The explosion and subsequent fire occurred on August 15th, 2016, while the ship was performing cargo operations in the Port of Colombo in Sri Lanka. The containers were two ordinary $40 \mathrm{ft}$. general purpose cargo containers, weighting 16.692 and 17.417 tonnes. The containers carried 26 and 25 pallets with 104 and 100 drums of lithium-ion batteries destined for recycling. An indication of the fire was initially discovered by crew members securing lashings around cargo hold 5 (location of the fire). Before they had the chance to inform the officer on watch, an explosion occurred. During the following days, a series of extinguishing techniques were attempted, initially water and $\mathrm{CO}_{2}$ were utilised, but did not have the desired effect. As the ship was at berth, the on-shore fire department were able to provide the ship with a high expansion fire extinguishing foam, which succeeded in dealing with the fire.

- 2012 - MSC Flaminia - Divinylbenzene, will be denoted as DVB (BSU 2014). MSC Flaminia is a $300 \mathrm{~m}$ long container ship sailing under German flag. During the fire and subsequent explosion, the ship had 23 crew members and 2 passengers traveling to Europe. The fire occurred during a voyage from Charleston in the United States to Antwerp in Belgium, more specifically on open sea in the North Atlantic Ocean. As a consequence, three crewmembers 
lost their lives, two were severely injured, the ship and cargo suffered extensive damage. Smoke was detected on the 14th of July in the morning. The sample extraction smoke detection system on the bridge indicated presence of smoke in cargo hold 4. At that time only two crew members were on shift. Upon inspection, the seaman confirmed that smoke was coming from the cargo hold. To alert the remaining crew the fire alarm was sounded, the crew was mustered and $\mathrm{CO}_{2}$ was deployed to combat the fire. Further, part of the crew was tasked with applying water to the area around and on the cargo hatch at cargo hold 4. During water application to the area an explosion occurred, which cut off crew in the fore part of the ship from the life boats and the rest of the crew. Following the explosion, the Captain decided to abandon ship. While performing the evacuation the crew trapped at the fore part of the ship were picked up. The ship was left to burn and the salvage operation was not concluded till the 9th of September.

\section{Cause-consequence analysis of the fires}

In order to analyse the risk associated with the containerised shipment of the identified hazards, a cause-consequence study was conducted. The study allowed the authors to investigate the occurrence of critical events by analysing potential causes for the realisation of such events combined with the consequence chains arising from these hazardous events. A representation of the overall structure of the analysis concept is given in Figure 1. This provides a typical template for producing a cause-consequence diagram (Nielsen 1975). The causes of the critical event are traced through a fault-tree analysis, while the consequences are analyses through cause and consequence relations. Depending on the level of detail the analysis is performed, the final consequence may be human casualties, major damage to an asset, or other. 


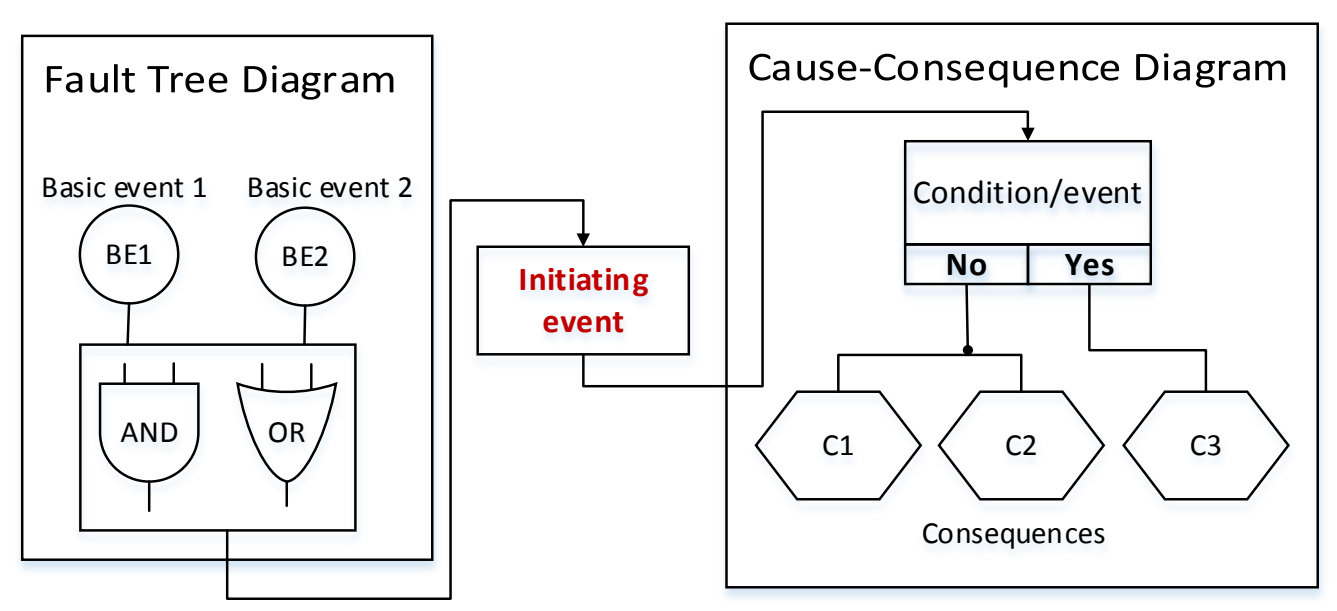

Figure 1. Template for a combined fault tree and cause-consequence diagram

A fault tree analysis is a well-known analytical technique and graphic model of the various parallel and sequential combinations of faults and conditions that result in the occurrence of a predefined undesired event. This event is referred to as the top event of a fault tree. In Figure 1 it is called "Initiating event", as the occurrence of such unwanted event requires activation of safeguards to stop an escalation.

Basic events on a fault tree are those that do not require further development, for one reason or another. There are two types of gates: the OR-gate and the AND-gate. The OR-gate is used to show that the output event occurs only if one or more of the input events occur. The AND-gate is used to show that the output fault (or an unwanted event) occurs only if all the input faults (conditions) occur. For details on a fault tree analysis see, for example, NUREG (1981).

The cause-consequence diagram, which follows the unwanted initiating event, describes different possible event sequences. They occur if one or more of the accidentpreventing actions (designed safety actions) fail or some other events or conditions serve as promoters of accident escalation. For details on construction of cause- 
consequence diagrams and conducting of a cause-consequence analysis see, for example, (Nielsen 1975).

Accident scenarios of the four fires described in the previous section have been elaborated in the form of cause-consequence diagrams. Additionally, the individual accident sequences were marked onto those diagrams, using an approach called the accident anatomy method (Bruun et al. 1979). The approach allows visualising the accident escalation paths for different cases which happened to take place in the past. An example is shown in the next section in Figure 3. Notations used on causeconsequence diagrams seem to be self-explainable.

\subsection{Calcium hypochlorite}

The critical or primary event investigated in this study was the decomposition of CHIO. Anhydrous and hydrated calcium hypochlorite product, respectively UN2880 and UN1748, are relatively stable products at normal ambient temperature. However, contaminants, higher than normal ambient temperatures, packaging sizes and moisture influence the stability of calcium hypochlorite products in a potentially hazardous way. As seen from the cause part of the cause-consequence diagram, Figure 2, which is the fault tree, several trajectories to the critical event exist. These are based on the results of the analysed accidents and provided in the thesis by Callesen and Blinkerberg-Thrane (2017).

By assessing the consequence part of the cause-consequence diagram, a series of possible external and internal heat sources have been identified. External heat sources are present throughout the cargo storage areas of a container ship. This is also acknowledged by International Maritime Dangerous Goods Code, which has implemented provision on where calcium hypochlorite products should be stored. However, above the weather deck infra-red solar radiation has been identified as a 
major contributor to heating up general purpose cargo containers. Temperatures inside a general purpose container can reach $50^{\circ} \mathrm{C}$ from effects like this. In terms of machinery, reefer containers may also serve as a heat source as the integral refrigeration unit's condenser is designed to remove heat from the reefer containers internal space and to release the heat outside the container. Below the weather deck several more heat sources are present, but the sun has however limited effect on these containers. The areas below the weather deck house a series of machinery, piping and equipment in general, which are critical for normal operation of a container ship. Most container ships operating internationally utilise highly viscous fuel oil as the primary fuel for propulsion. The fuel storage and settling tanks are equipped with heating coils that usually carry steam to heat the surrounding fuel oil. Storage tanks are, by recommendation of class societies, heated to approximately $10^{\circ} \mathrm{C}$ above the fuel oil's pour point, which for most standard fuel oils is approximately $30^{\circ} \mathrm{C}$. Further, settling tanks are heated to $60^{\circ} \mathrm{C}$ and more. In many cases the surface temperature of these tanks is in the range of $70-80^{\circ} \mathrm{C}$, as estimated by the German Federal Bureau of Maritime Casualty Investigation in their investigations of the fire aboard CMV PUNJAB SENATOR (BSU 2006).

Apart from heat, reducing agents like glycerol or sulphur will react spontaneously and violently if CHIO comes into contact with such contaminants. Further, moisture and UV radiation may cause an increase in the concentration of chlorates (strong oxidiser) present in the batch, making it more prone to combust. Lastly, a container in which CHIO is stored can be defective possibly resulting in further decomposition of CHIO by the influence of the accumulated heat. In this case, the reaction may become self-perpetuating, causing a runaway-reaction. Figure 2 summarises the causes resulting in decomposition of CHIO. 


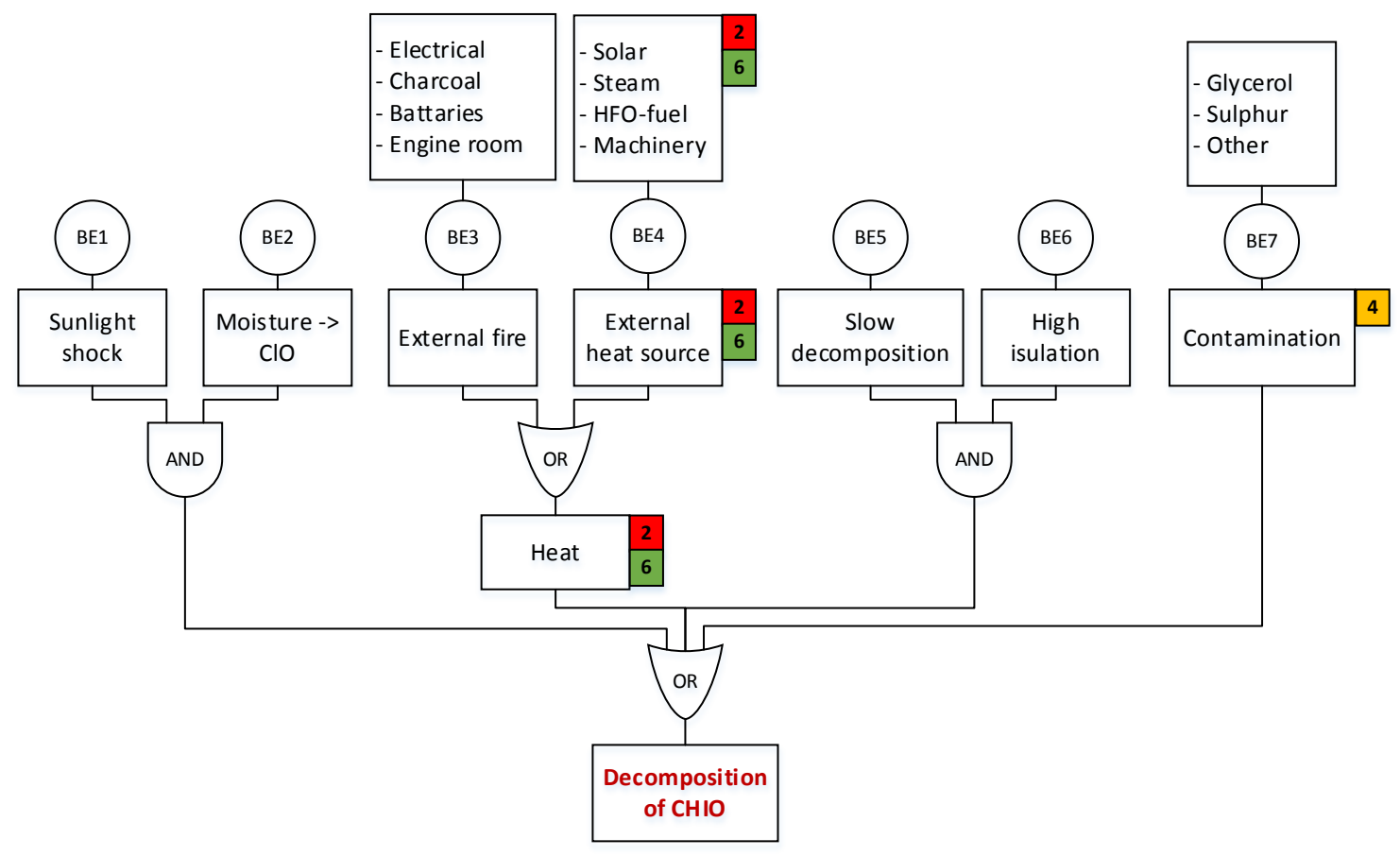

Figure 2. The fault tree diagram for calcium hypochlorite

In Figure 2 and Figure 3 the different real-life case trajectories have been marked on both the cause and the consequence part of the cause-consequence diagram. The numbers link to the following ships (Table 4):

Table 4. List of ships which have had major fires aboard due to calcium hypochlorite

\begin{tabular}{|l|l|}
\hline [1] CONTSHIP FRANCE - YEAR 1997 & [6] SEA ELEGANCE - YEAR 2003 \\
\hline [2] ACONCAGUA - YEAR 1998 & [7] AMSTERDAM BRIDGE - YEAR 2012 \\
\hline [3] DG HARMONY - YEAR 1998 & [8] HANSA BRANDENBURG - YEAR 2013 \\
\hline [4] CMA DJAKARTA - YEAR 1999 & [9] HANJIN GREEN EARTH - YEAR 2015 \\
\hline [5] HANJIN PENSYLVANIA - YEAR 2002 & [10] MAERSK SEOUL - YEAR 2015 \\
\hline
\end{tabular}

By focusing on the causes which led to the occurrence of the actual fire incidents, we could see that limited information was available about this initial phase. The reason might be that following the ignition of such fires, a rapid or slow fire progression will 


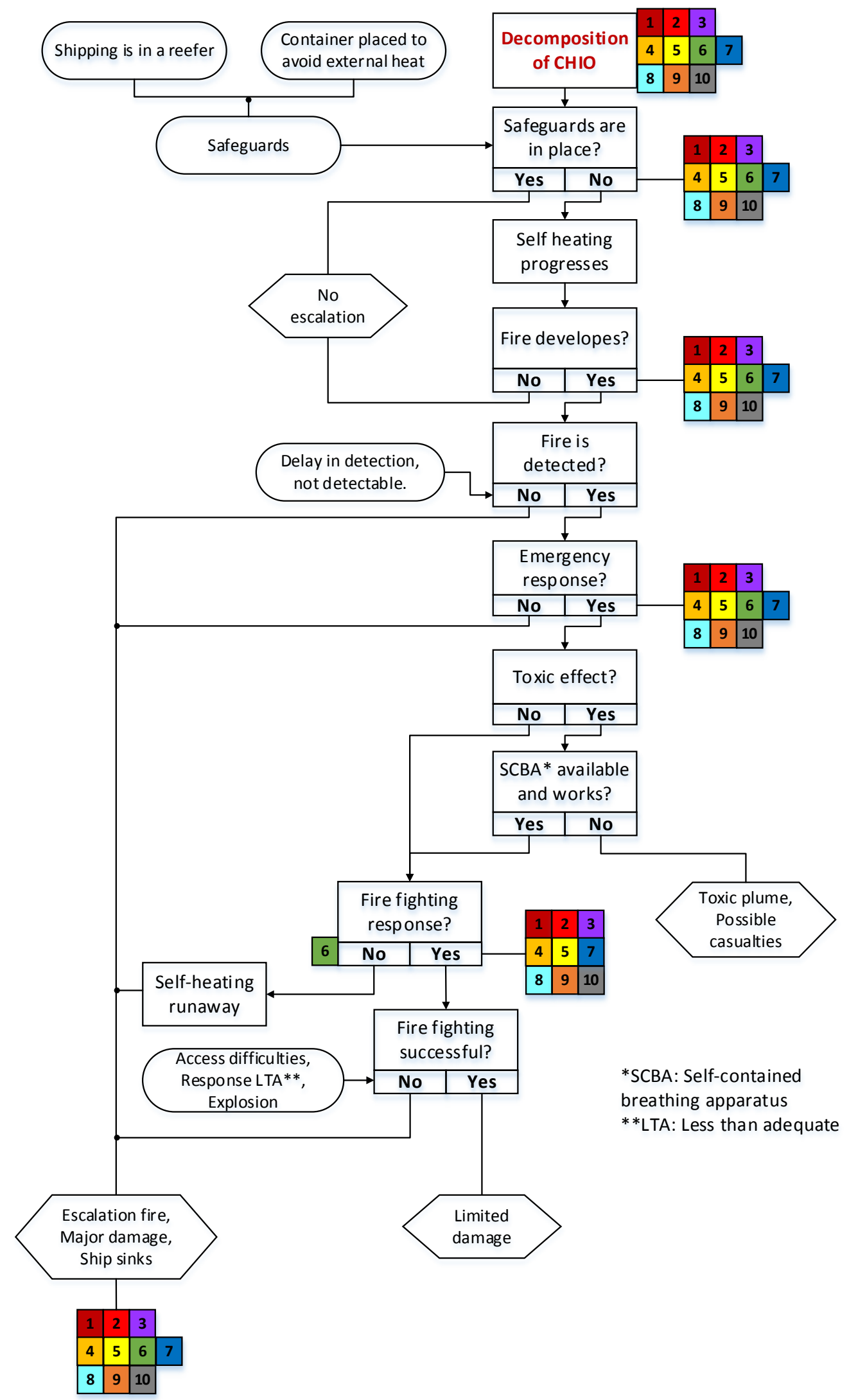

Figure 3. Cause-consequence diagram: Calcium hypochlorite’s escalation paths 
occur, which is also mirrored through the cause-consequence relations. The progression of these fires will often make it difficult to determine the actual cause of ignition as most of the evidence is lost as a consequence of the fire. This also emphasises the importance of conducting risk analyses, as they improve the ability to predict the general causes for the ignition of fires, thereby allowing safety engineers to reduce the probabilities of these fires by trying to prevent the discovered causes or mitigate the consequences.

Through investigation of the 10 discovered real-life fire scenarios it was possible to identify the actual cause of the critical event for three fire scenarios, namely case 2, 6 and 4, as seen in Figure 2. In case 2 and 6 the discovered cause of the fire/explosion was due to a container carrying $\mathrm{CHIO}$ that had been stored next to a HFO tank, causing the internal temperature of the container to increase during the voyage of the container ship. The fire incident in case 4 was allegedly caused as a result of impurities in the stored CHIO which caused the cargo to self-combust leading to an explosion of the container followed by a severe fire.

When comparing the consequence chains attained in the cause consequence diagram with the actual escalation paths of the real-life fire scenarios, one can see that almost all of the fire incidents can be linked to the same path of escalation. Further, it can be seen that all of the discovered fire accidents, which initiated because of the decomposition of CHIO, resulted in major damage to the ship and containerised cargo. This strongly indicates to that $\mathrm{CHIO}$ is a high-consequence hazard with regard to the fire safety aboard container ships.

\subsection{Charcoal}

Charcoal is prone to self-ignition if kept in large densely packed quantities at elevated ambient temperatures (Walters et al. 2003). This may produce a situation in which 
thermal runaway occurs. Thermal runaway is a condition in which more heat is generated inside the system then is lost to the surroundings, causing an elevated temperature inside the system and may lead to self-ignition of the charcoal. Thermal runaway has therefore been identified as the sole critical event through hazard identification. This state may be caused by several different initiators. Most are not different from the causes described in the previous cause-consequence analysis and will therefore only be summarized. To present the causes of such an event in a clear fashion the cause part of the cause-consequence analysis diagram is presented in Figure 4. The event tree part of the cause-consequence diagram is not shown in this paper and can be found in Callesen and Blinkenberg-Thrane (2017).

From hazard identification, it was established that densely packed bags of charcoal with a radius of $1.25 \mathrm{~m}$ may produce conditions where the critical ambient temperature (CAT) is reduced to approximately $52^{\circ} \mathrm{C}$. In some scenarios heat sources may produce ambient temperatures in this vicinity. As mentioned previously, this includes heating from adjacent HFO-tanks, steam, external fires and various machinery. Above the weather deck the main external heat source is the sun. "Hot stow" cargo may be heated sufficiently to experience internal temperatures in the area of the CAT. Significantly different to these are two causes related to internal self-heating. These are applicable both above and below the weather deck. As charcoal contains organic matter, bacteria may inhabit it and metabolise it. Such activities produce heat, in the same fashion as seen in compost piles. Bacterial heating may increase the internal temperature of the charcoal, up to $80^{\circ} \mathrm{C}$, as described in (Walters et al. 2003). This is well above the CAT established previously and may cause a thermal runaway reaction and possibly self-ignition. Further, vibration-induced friction was considered. Vibration is present throughout a ship, in varying degrees. These are produced by the main engine, 
auxiliary machinery, pressure induced on the hull surface by the propeller and waves acting on the hull. Vibration could cause internal friction between the individual charcoal briquettes. This could produce areas in-between the briquettes with high temperatures and possibly thermal ignition. Such a scenario could therefore very well cause the critical event.

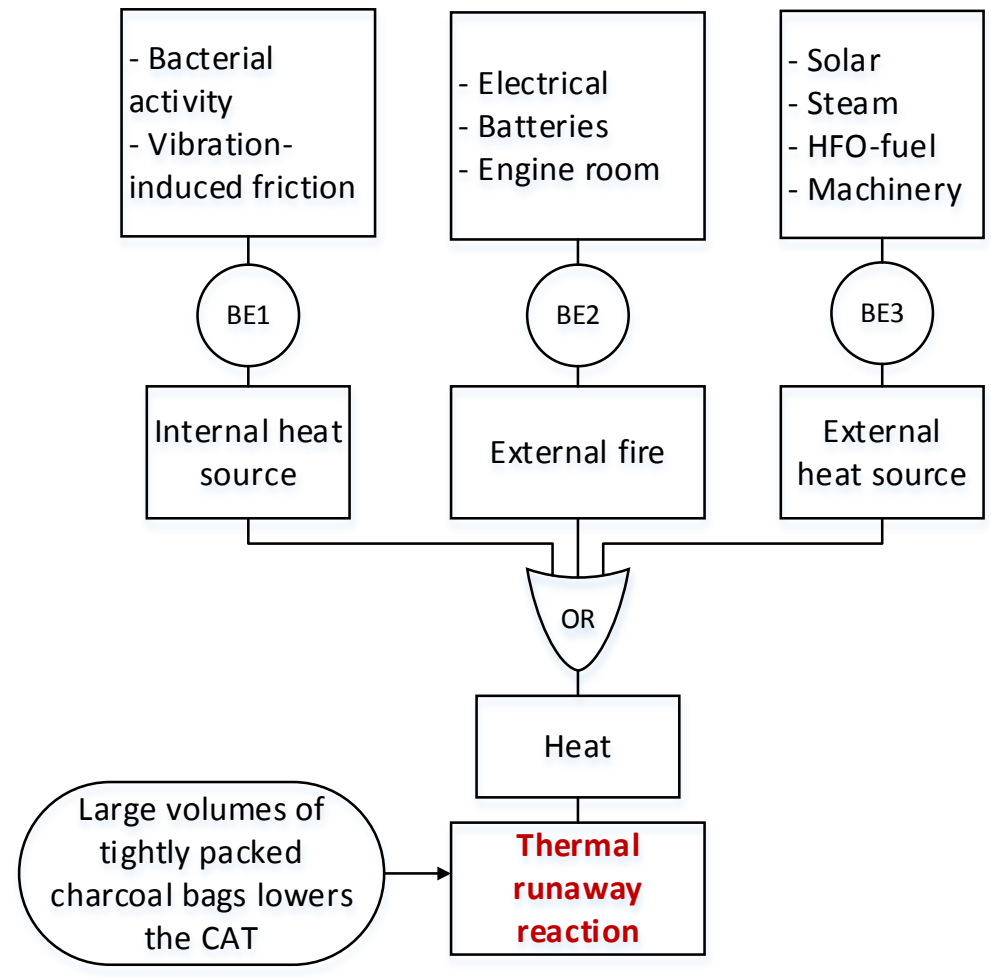

Figure 4. A fault tree diagram for charcoal

\subsection{Lithium-ion batteries}

Analysing the fire accident case resulting from lithium-ion batteries, the critical event identified as most likely to occur was a thermal runaway reaction (Callesen and Blinkenberg-Thrane 2017). The causes of such event vary to some extent, but essentially it occurs when the anode and cathode come in direct physical contact with each other. The first cause considered is a short-circuited battery, which might produce enough heat to melt the polyethylene liner between the cathode and anode. Trajectories 
for producing a short-circuit are vibrations, errors in design or assembly and insufficient packaging material.

Vibrations may cause individual batteries to rub against each other, which in turn could penetrate insulation material set in place to ensure that the cathode and anode do not come into contact which each other. Further, a design error or assembly of a battery, similar to that of the batteries in the Samsung smart phones that vented with flame, could produce an internal short- circuit leading to the critical event described. Inadequate packaging of batteries, like in the case of CMA CGM Rossini (BEAmer 2017), has likely caused these to tumble around inside the container or in the packaging, allowing the terminals to touch one another. Lastly, punctured cells are considered, which may occur if the batteries are subjected to mechanical impact through rough handling in combination with sharp edges. A punctured cell would cause direct contact between the cathode and anode of the battery.

Similar to the previous cases, external heat sources are considered as well as a cause of a battery fire. Lithium-ion batteries may vent with flame if heated. However, a study by (Hess 2015) showed that $150^{\circ} \mathrm{C}$ was the lowest onset temperature at which thermal runaway occurred in ordinary consumer batteries. This study was performed on single batteries. Investigations on batteries stored in bulk were not discovered in this study. From studies on other products that are prone to thermal runaway reactions, bulk storage tends to lower the critical ambient temperature. For this reason, external heat sources are considered a potential cause of the critical event. Also, external fires in adjacent containers could provide the onset temperatures of $150^{\circ} \mathrm{C}$ to $210^{\circ} \mathrm{C}$ that have been shown to produce rapid thermal runaway reactions in ordinary consumer batteries. Figure 5 shows the cause part of the cause-consequence diagram relating to lithium 
batteries. The consequence part of the cause-consequence diagram can be found in (Callesen and Blinkenberg-Thrane 2017).

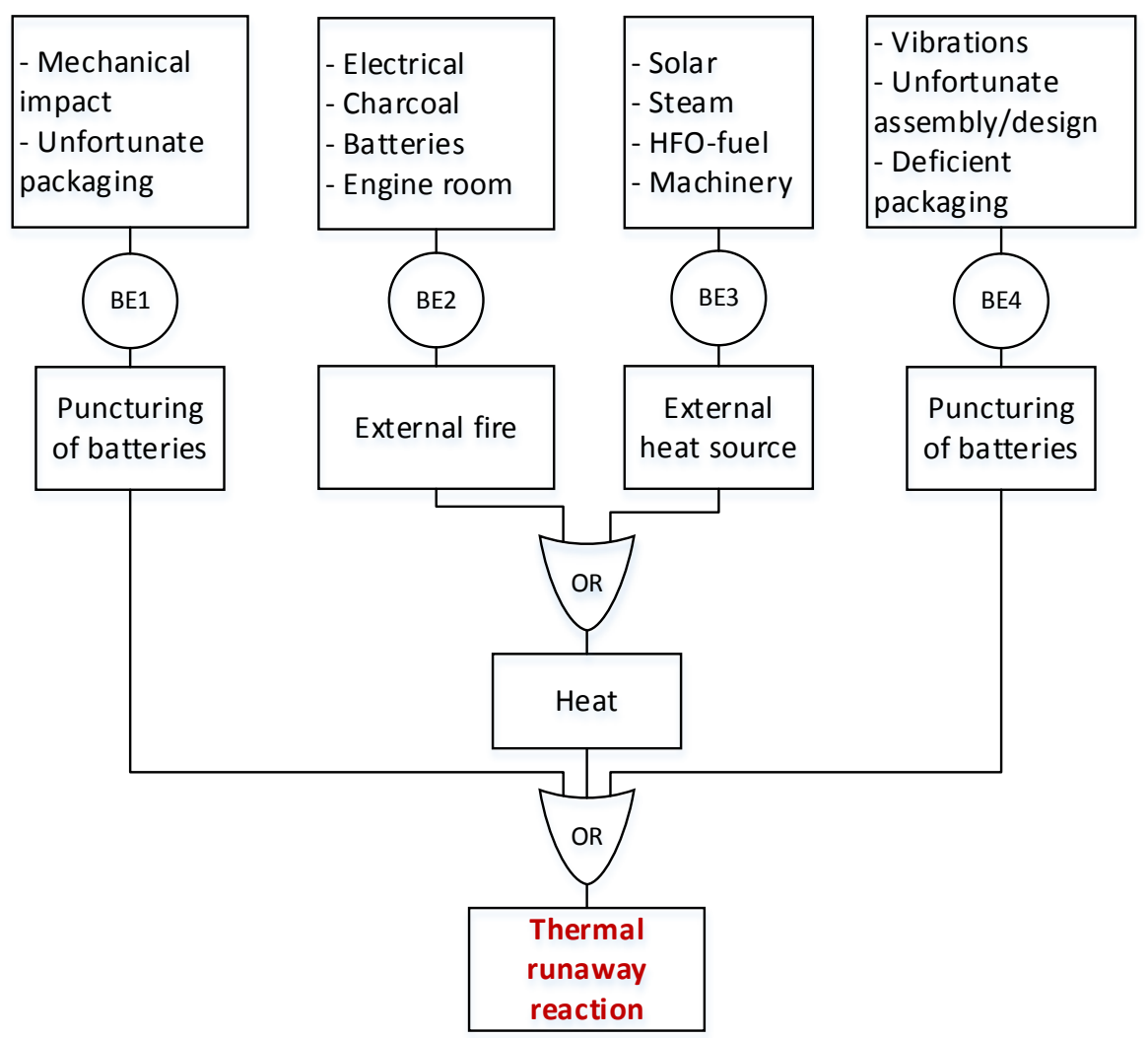

Figure 5. A fault tree diagram for lithium batteries

\subsection{Divinylbenzene}

DVB, a monomer used in polymerisation reactions, may polymerise and produce heat.

The reaction is accelerated with increasing temperature and may cause a thermal runaway reaction. The potential causes of such an event have been established as external heating, contamination and limited available TBC (tertiary-butyl- catechol) the polymerisation inhibitor used for stabilising the product. Further information regarding DVB can be found in (DCC 2010)

TBC relies on available oxygen to limit the amount of DVB polymerising spontaneously. The depletion rate of TBC increases with temperature, i.e. higher than normal ambient temperatures cause TBC to deplete quicker. Considering this, a series 
of trajectories lead to the critical event, i.e. polymerisation of DVB. These include polymerisation of DVB due to external heat sources, unfortunate batch with insufficient TBC and/or oxygen and contaminants. Sources of increased external temperatures have been elaborated upon earlier, in the cause-consequence analysis on calcium hypochlorite. Low inhibitor levels may occur if the product has not been stored properly or improper quality control at the producer causing a bad batch to leave the factory. As TBC relies on available oxygen to inhibit polymerisation, if aeration has not been performed prior to shipment the TBC will be rendered useless. Lastly, the possibility of contaminants is considered. As DVB is transported in tank containers, entry of contaminant into the cargo while it is in transit seems unlikely. However, if DVB were to be contaminated by catalysts, acids or oxidisers this could cause the DVB to polymerise violently. Figure 6 shows the cause part of the cause-consequence diagram relating to DVB.

\section{Estimation of fire accident frequencies}

The collected data on fire accidents (Appendix), complemented by the data on the number of active container ships operating each year (UNCTADSTAT 2017), allow the assessment of fire accident frequencies. The method hereof is described in (Spouge 1999). The collection of data on the number of active ships was started by the United Nations Conference on Trade and Development Statistics (UNCTADSTAT) in 2011. Also, the study reported her terminated before the end of 2017 and therefore it would not be incorrect to include the fires that occurred this year. Hence, the frequency assessment period covers the time span 2011-2016, both years included. The data on the global fleet of container ships needed for the assessment are summarized in Table 5. 


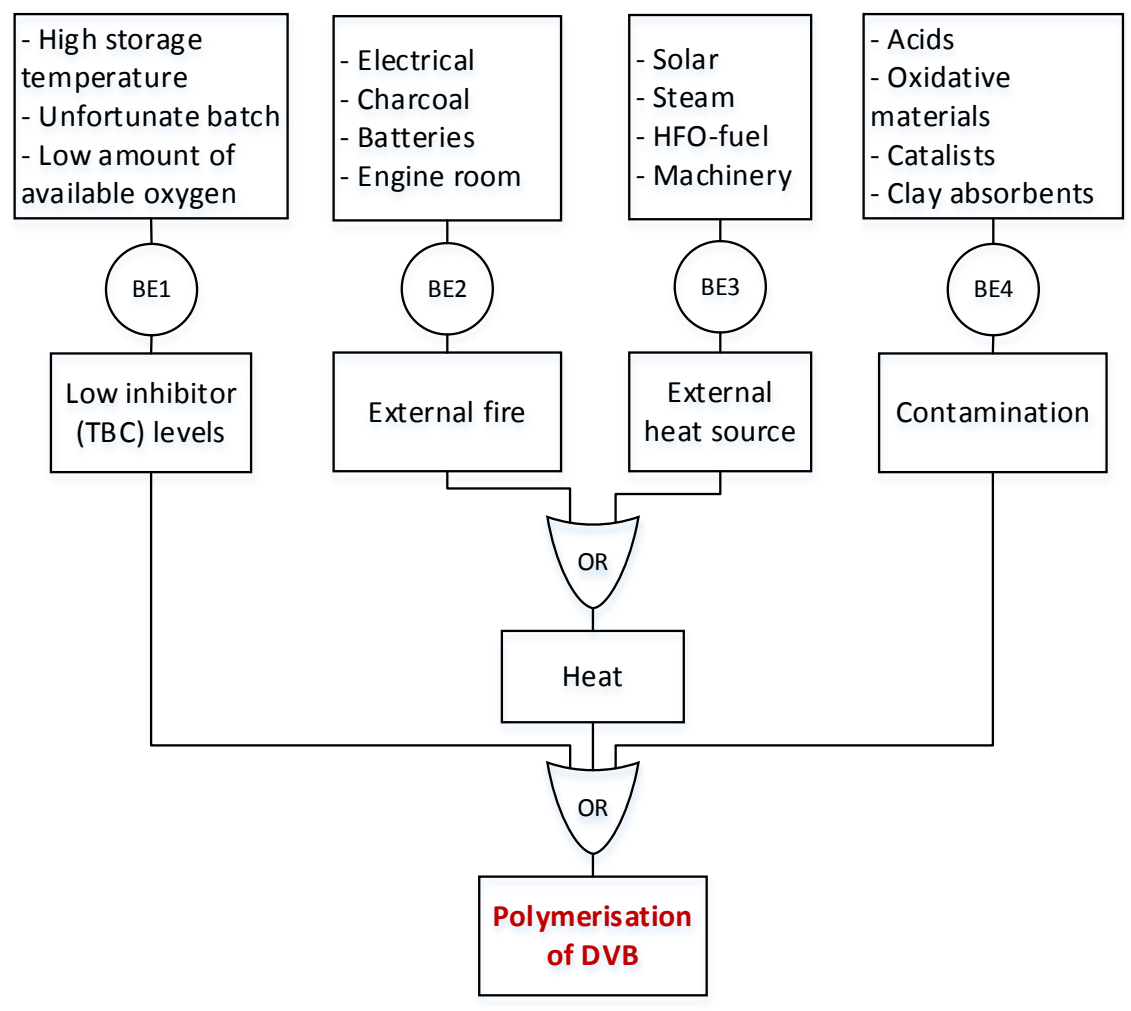

Figure 6. A fault tree diagram for DVB

Table 5. Data for the assessment of fire accident frequency of container ships

\begin{tabular}{|l|r|r|r|r|r|r|r|}
\hline \multicolumn{7}{|c|}{ Global fleet of container ships } \\
\hline Year & 2011 & 2012 & 2013 & 2014 & 2015 & 2016 & 2017 \\
\hline Number of ships & 4,966 & 5,096 & 5,107 & 5,101 & 5,111 & 5,226 & 5,154 \\
\hline $\begin{array}{l}\text { Size of fleet in } \\
\text { DWT }^{3}\end{array}$ & 183,691 & 196,821 & 206,547 & 216,199 & 228,230 & 244,339 & 245,609 \\
\hline Number of fires & 0 & 2 & 4 & 2 & 11 & 2 & 1 \\
\hline
\end{tabular}

As the number of fire events are rather limited from a statistical point of view, deriving confidence limits would provide the range which most probably covers a true value of the frequency. Thus, a 90\% Chi-squared confidence interval was calculated and the expected frequencies of major cargo fires are presented in Table 6. From the estimates it is seen that such a fire occurs between 4.56 to 9.94 times per 10,000 ship years.

\footnotetext{
${ }^{3}$ Dead weight tonnes
} 
Table 6. Estimated cargo fire frequency

\begin{tabular}{|c|l|l|c|c|c|}
\hline Period & Cargo fires & Ship years & \multicolumn{3}{|c|}{ Fires per ship year } \\
\cline { 4 - 6 } & & & Best estimate & Lower limit & Upper limit \\
\hline $2011-2016$ & 21 & 30,607 & $6.86 * 10^{-4}$ & $4.56 * 10^{-4}$ & $9.94 * 10^{-4}$ \\
\hline
\end{tabular}

Such frequencies can be used in determining the justifiable investment or performing a risk evaluation towards the ALARP-principle of risk acceptance. In the following we provide the calculation of justifiable investment in preventing fires. Of course this calculation is quite approximate, but is sufficient to justify further investigation of the concept.

As exemplified in Table 2, the cost of the total loss of a container ship of 19,000 TEU is amounted to about $\$ 1$ billion. However, this type of consequence is very rare. A more frequent consequence of fire on board would be a partial cargo loss, expenses on removal of wreck and liabilities as well as repair costs for the ship. Assume the consequences of a fire constitute one fifth of the total loss, which is $\$ 0.2$ billion. The expected loss, which does not include implied cost of loss of life, is then the following:

Expected loss per year $=$ Frequency per year $*$ Loss $=6.86^{*} 10^{-4} * \$ 0.2^{9} \approx \$ 1.3 * 10^{5}$.

For justifiable investment this cost per year is capitalised either by discounted cash flow calculation, or by years to return on investment. For safety systems a typical period required for return of investment is 5 to 10 years, giving a justifiable investment for improved fire protection of $\$ 0.65$ million to $\$ 1.3$ million.

Provision of in-container detection would require instrumentation for some 19,000 containers, so the maximum justifiable investment per container would be about $\$ 35$ - \$70. This is not beyond the limits of feasibility - RFID-based temperature sensors are available for under $\$ 10$, and avoid the need for batteries. Providing instrumentation 
for just the containers with the most critical cargoes would make this approach definitely economically feasible. There are however organisational difficulties primarily the questions of who should pay and the question of how the cargo types could be registered.

It remains to be said that NORSOK’s standard Z-013 on risk and preparedness analysis suggests an acceptability criterion of an annual frequency of $1 * 10^{-4}$ per accident "load". Meaning that a single type of accidents like cargo container fire may not occur more frequent than $1 * 10^{-4}$ per ship year.

\section{Fire detection system}

From the presented cases and the analyses it was concluded that the typical problem of the crew was to identify where the affected container was located and to have timely detection. Specifically, the detection system should be able to provide the crew with an exact location of the fire and be able to do so before a fire becomes uncontrollable.

Through a brainstorming session, the ideas were generated and summarised in Table 7. These ideas cover a wide range of technologies, but the remaining part of the article will focus on developing the temperature and smoke detector concepts.

Table 7. Results of silent brainstorming

\begin{tabular}{|c|l|l|}
\hline No. & Solution technology & Placement \\
\hline 1 & Temperature sensors & Installed in all containers \\
\hline 2 & Thermal imaging camera (TIC) & Above or below the weather deck \\
\hline 3 & Smoke detector (wireless) & Installed in each container \\
\hline 4 & Sniffer (aspirating) smoke detector & $\begin{array}{l}\text { Either installed in each container, at the } \\
\text { container vents or near each container row }\end{array}$ \\
\hline 5 & $\begin{array}{l}\text { Infrared spectroscopy - CO/CO } 2 \text { detection } \\
\text { (linear or optical) }\end{array}$ & $\begin{array}{l}\text { Installed in each container or installed to } \\
\text { properly overview all containers }\end{array}$ \\
\hline 6 & Gas detector (chlorine or flammable gas) & Installed in all containers \\
\hline 7 & $\begin{array}{l}\text { Unmanned aerial vehicle (UAV) for fire } \\
\text { development monitoring }\end{array}$ & Above or below the weather deck \\
\hline
\end{tabular}


To investigate the possibilities of placing temperature sensors in or on shipping containers, the technologies behind measuring temperature were investigated in (Callesen and Blinkenberg-Thrane 2017). The main conclusions hereof were that temperature sensor technologies are very well established, and could be acquired at low unit cost.

In developing the concept it was meant that making the connect data cables on every transfer of containers should be avoided. Therefore, it was decided that the sensors should be able to communicate via a wireless connection to decentral receivers located throughout the ship. The temperature sensor would simply transmit the present temperature and the containers serial number. These would then answer to a central control station evaluating changes in temperature relative to the ambient temperature of the cargo space or outdoors temperature, as shown in Figure 7. The serial number could be compared to the locations of each container available in the loading computer. With an internal or external temperature sensor, it would be possible to detect a thermal runaway prior to the internal material igniting or the reaction becoming uncontrollable. All in all, the crew would be provided with an alert for an affected container and its location.

Both the sensor and wireless transmitter would require a power source. A battery is the obvious choice in providing this. Depending on the power consumption of such setup, it would require recharging preferably not more frequent that in the 5-year servicing cycle that containers undergo. Otherwise, charging can possibly be achieved through an inductive charging coil placed on land or similar.

From the session, a discussion on the advantages and disadvantages of mounting temperature sensors inside every container was conducted. In terms of advantages, the idea of having a fast response time was brought forward. It was established in plenum 
that e.g. a runaway reaction or similar would be detected faster than through other methods, as such a reaction would produce significant quantities of heat prior to ignition.

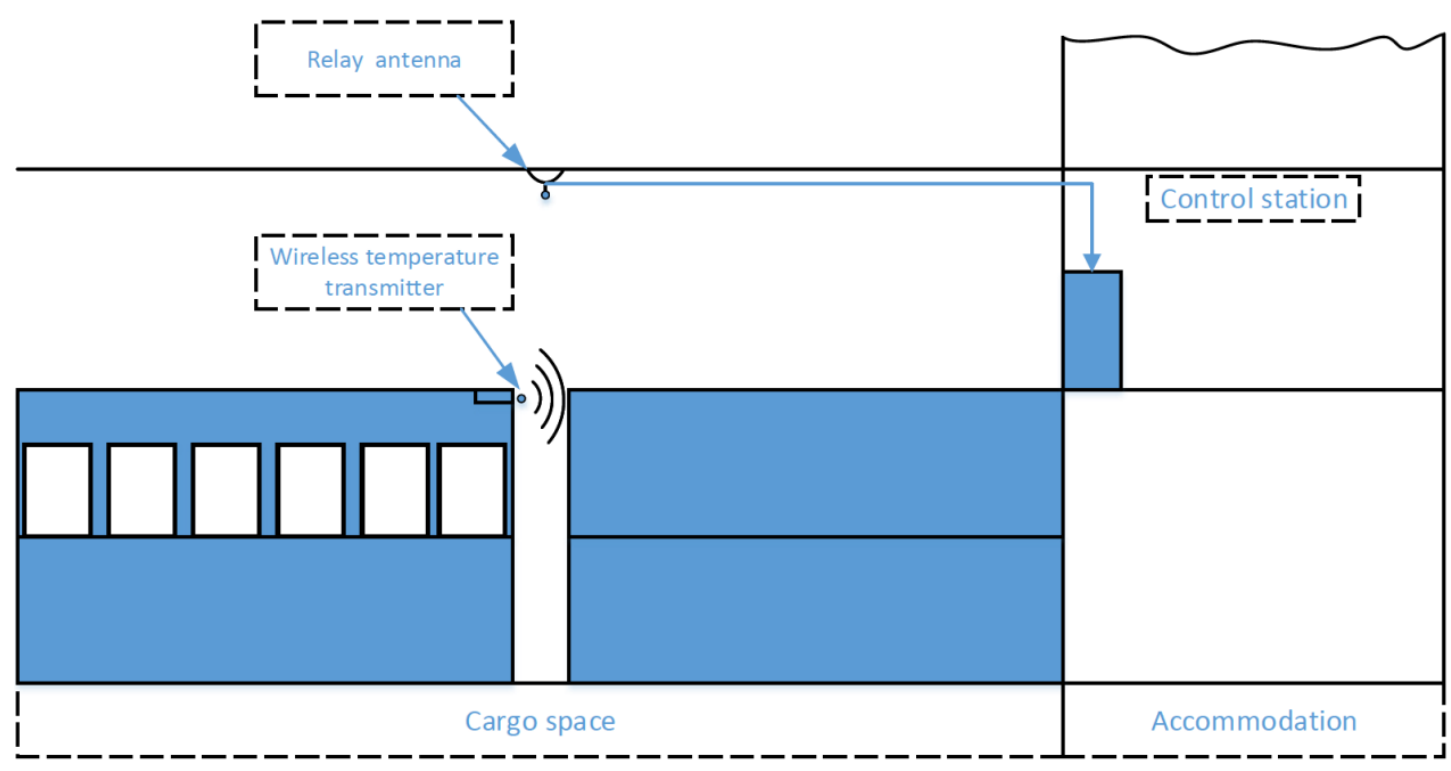

Figure 7. Temperature sensor concept

The large amount of temperature sensors to be installed is the main disadvantage along with standardization. Expenditures from purchasing a IC-type temperature sensor may be in the range of $3-4 \$$, along with a wireless transmitter at $4-5 \$$ and a battery in the same price range and putting these together may produce a product in the $20 \$$ range. Development could reduce this price. RFID tags, for example, are available with miniature enclosures for $1 \$$ or less. However, as an ultra large container ship carry upwards of 20,000 TEU (predominantly $40 \mathrm{ft}$. containers), more than 10,000 sensors would be needed for one installation. The global fleet of container ships currently include 5,154 ships, making the quantity of sensors required to be installed globally quite large. In addition to this, standards must be in place so that the equipment aboard a Maersk vessel is compatible with a MSC vessel and so on. Such challenges are usually 
resolved in within the ISO, but the prospects may be long, depending on differences among stakeholders.

Secondly, as the temperature sensor device would provide the serial number of the affected container, the location of the container could be identified. Locating the affected container, especially under the weather deck, is often a major challenge. Providing an exact location of the affected container would make this task considerably easier. This is considered an advantage.

As with virtually any equipment installed on a vessel, the temperature sensor device would require occasional maintenance. This is not an issue in itself, but the responsibility of performing the maintenance is necessarily placed on one of the interested parties. This should preferably be the owner of the container, who is also responsible for maintenance according to the requirements set out in the Convention on Safe Containers (CSC)-plate. Such responsibility would increase the operational expenditures of transporting containers.

Reliability of the sensor device and supplying it with power, are two relevant technical difficulties. From the interview with head of the Danish Maritime Accident Investigation Board Oessur J. Hilduberg, previous attempts at placing sensors in the containers proved ineffective due to damage inflicted on the equipment through use of the containers. This is of course a challenge, but it may be solved through improved design and environmental tests of the equipment.

To quantify the advantage of placing temperature sensors and/or smoke detectors in the cargo container it was decided to simulate a fire in such a container. This simulation was performed with the software Fire Dynamics Simulator (McGrattan and Hostikka 2017), which is described in the next section. 


\section{Modelling of fire escalation}

With reference to the cargos and witnessed fire accidents described in the previous section it was decided to develop a fire simulation model to investigate the response time of monitoring the temperature and smoke dispersion in a 40-ft. general purpose shipping container.

The model utilized for testing was built on a previous fire development study described in Callesen and Blinkenberg-Thrane (2017). The literature applied to develop this model was found in Gissi (2009). Adjustments were made to the affected container's surroundings to represent the geometric proportions of a 13,100 TEU container ship’s cargo hold located amidships. Further, instrumentation was added to the interior of the container and top of the cargo hold to evaluate temperature increase progress and smoke dispersion. The FDS-script written to run the simulation is available in appendices of Callesen and Blinkenberg-Thrane (2017). Figure 8 shows the modelled geometry of the cargo hold, including container and cargo. Just one container is shown, for clarity.

A simulated thermocouple and smoke detector were placed in the far-right corner of the container, indicated by the red circle in Figure 9. The parameter describing activation of an alarm was a chamber smoke density obstruction threshold which was varied to investigate response time.

To indicate when smoke would be possible to detect at the top of the cargo hold, two smoke detectors were implement in a location just below the hatch cover. These were provided with the same detection parameters as the one location inside the container. 


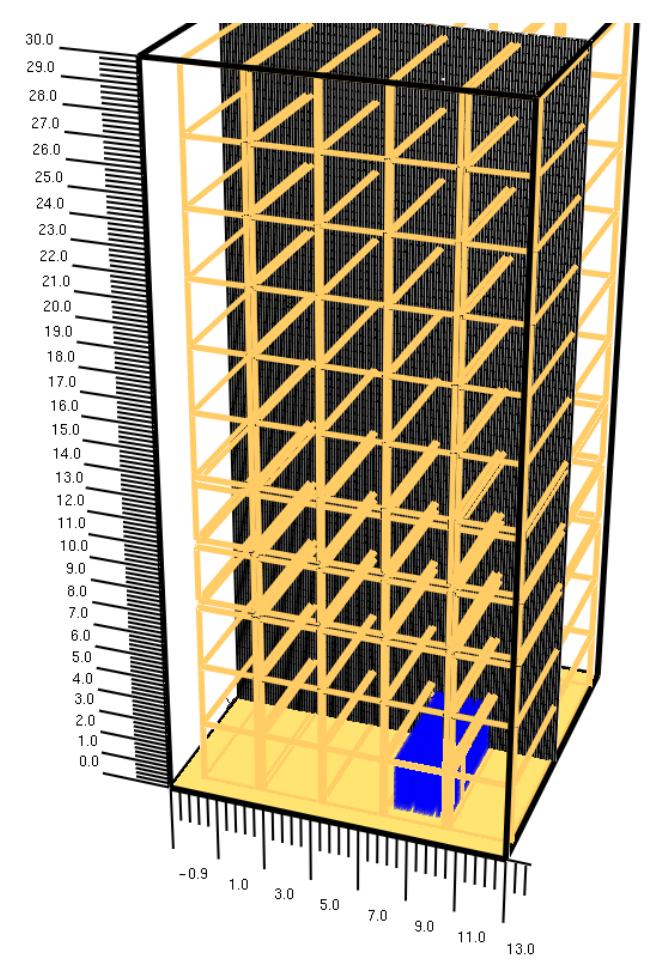

Figure 8. Picture of the modelled cargo hold with smoke dispersion calculation results

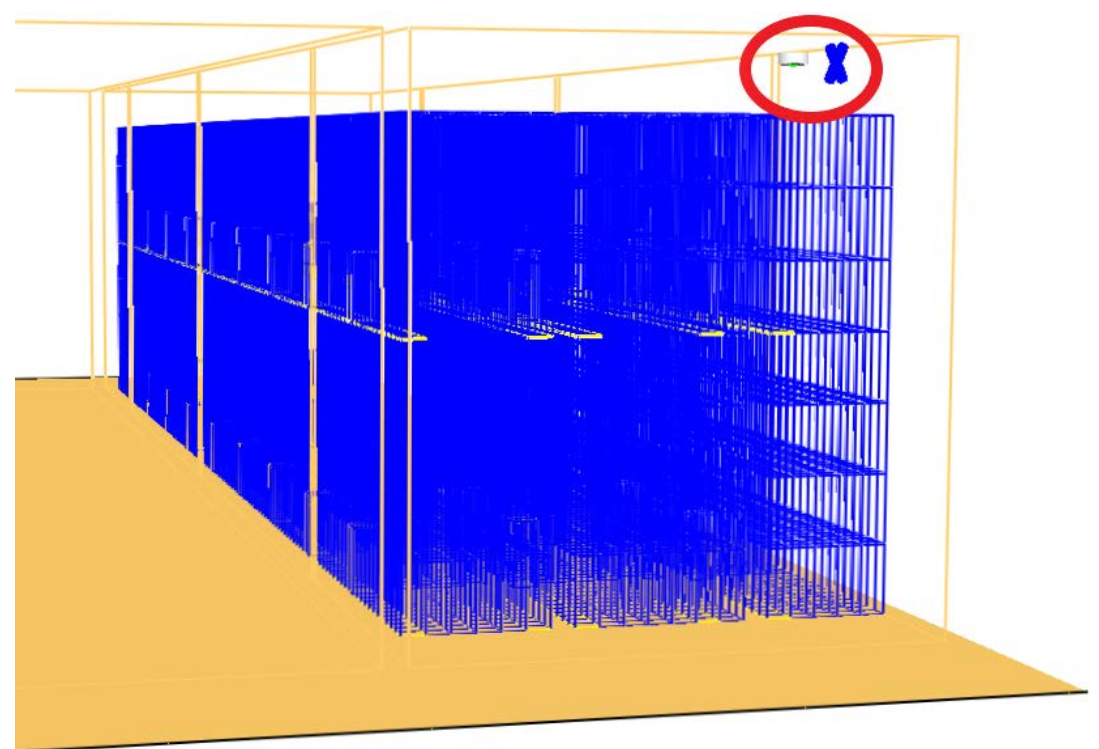

Figure 9. Picture showing a box filled container and the instrumentation placed in it

From the simulation, results concerning temperature and smoke detection were obtained. These are presented in Figure 10, where temperature and measured smoke 
obstruction are plotted as a function of time. Here it is important to keep in mind that the smoke detectors are activated at 3.28\% obstruction meaning that the internal smoke detector is activated between 29 and 30 seconds, while the smoke detectors located at the top of the cargo hold are activated approximately between 60 and 74 seconds during the simulation. The centrally placed smoke detector is activated firstly and the one placed in the proximity of the cargo hold is activated lastly. Concerning the thermocouple, this begins to register changes in temperature after 27 seconds. The relevant data file obtained via the simulation can be seen in appendices of Callesen and Blinkenberg-Thrane (2017). Also the output file from FDS, further soot dispersion, flame and oxygen mass fraction plots are placed in the appendices of the named thesis. Note that for large scale utilisation of this concept, the detector(s) would need to be of solid state type for price reasons.

The "full" simulation allowed the dispersion of smoke in a complete hold. With detection within 30 seconds there is still considerable time left for firefighting before the fire becomes uncontrollable.

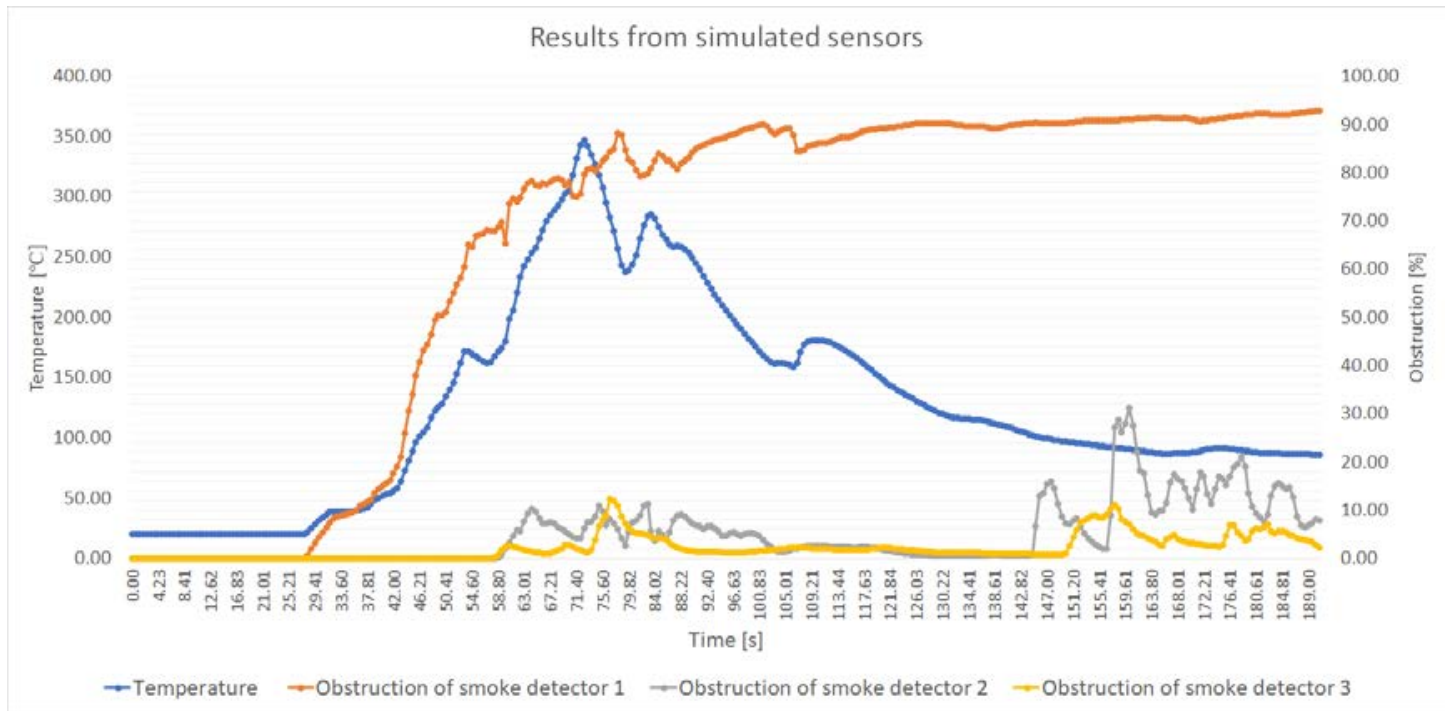

Figure 10. Results of the simulated sensors. Temperature and smoke response 


\section{Conclusions}

Through the course of the study of fire accidents, 39 confirmed container ship fires were discovered by the authors in the period between 1996 - 2017. This was accomplished through extensive search and information retrieval from relevant web-based sources combined with investigations into the European Maritime Safety Agency’s register of maritime casualties. The aim of the hazard identification study was to investigate and classify the substances and/or articles, which could be identified as the main hazards to the fire safety aboard container ships. This was done through extensive in-depth analysis of the discovered container ship fire cases and their apparent causes.

In this way the authors were able to identify containerised shipment of calcium hypochlorite and compressed charcoal briquette products as being the main hazards. This was concluded based on the large fraction of fire incidents, caused by the shipment of these two types of cargo. Calcium hypochlorite and compressed charcoal briquette products combined constituted the cause of almost $50 \%$ of all the explored fire accidents. It should also be noted, that the fraction of fires, in which it was not possible to identify the cause of fire accidents, represents $19 \%$ of the investigated cases. The discovery of these causes could therefore further increase the fraction of fires caused by calcium hypochlorite and compressed charcoal briquette products.

Containerised shipment and storage of rechargeable batteries and divinylbenzene are also high consequence hazards, as the severity of the fire accidents and the extensive damage these two types of cargo fires inflicted on both the container ships and their crew. For a better understanding of the chemical nature of the identified hazards, a chemical study was conducted, a description of which is not included in this paper. 
To determine the actual frequency at which cargo fires occur aboard container ships, a frequency study was conducted as well. A best estimate for the overall frequency of experiencing major fires aboard container ships in the period 2011-2016 was calculated as $6.86 \cdot 10^{4}$ per ship year, with a $90 \%$ chance that the actual frequency was within the interval $4.56 \cdot 10^{4}$ and $9.94 \cdot 10^{4}$.

Further, through the study seven ideas were put forward that potentially could reduce the response time needed to detect a possible source of fire and thereby improve the chance of suppressing the fire. By exploring the technologies that created the basis for the developed solutions, the solution ideas themselves, and conducting validation studies on the explored solutions, two solutions were considered worth further exploring:

(1) Placement of temperature sensors in or on all shipping containers; and

(2) Installation of an optical smoke detector in all containers.

In providing a basis for evaluating these solutions, a fire simulation study was performed. It was conducted through the computational fluid dynamic software Fire Dynamic Simulator. The aim of the study was to explore how fast a fire could be detected by temperature sensors in containers as opposed to current smoke detection systems in cargo holds. In the simulation, two smoke detection points were placed in the top part of the cargo hold in order to represent the actual placement of a sample extraction smoke detection (SESD) system, which is applied on some container ships. Further, it was explored how a placement of an optical smoke detector within the container would improve the response time of detecting smoke and to which degree.

From the study, it was discovered that the temperature sensor positioned within the container was able to detect a temperature increase, approximately 27 seconds after the ignition of the fire. This constitutes an improvement in detection response time from 
the SESD system of minimum 50\% (Detection interval from SESD detection points: 60 - 74 seconds). It was further discovered that by placing the optical smoke detector within the container, smoke can be detected within 30 seconds.

These results show a significant reduction in the detection time on board a container ship in case of a cargo fire. It is found that both solutions, to install either temperature sensors or smoke detectors in the containers, are viable from a practical point of view and experience; and that further studies towards the cost-effectiveness of the solutions are desirable.

Future work should consider the modelling of different improvements and setups of the firefighting system. It should further investigate and validate the solution space for improving the fire detection methods aboard container ships. Special attention should be given to the improvement of the suppression arrangements based on the findings of performed study. We also consider that research on the influence of organizational factors and management is a promising way of improving the efficiency of firefighting. A specific development worth further studying is the use of RFID technology with on-chip smoke sensing to enable early smoke detection. The main problem to be overcome is to enable RFID scanning within the container stacks. Overall, future work should focus on both preventing and protecting container ships and their crew against cargo container fires which will improve the fire safety aboard.

\section{References}

[Allianz] Allianz Global Corporate \& Specialty SE. 2015. Safety and Shipping Review 2015 - an annual review of trends and developments in shipping losses and safety. London: Allianz.

[Allianz] Allianz Global Corporate \& Specialty SE. 2016. Safety and Shipping Review 2016 - Loss Trends and Risk Challenges . London: Allianz. 
[BEAmer] Le Bureau d'enquêtes sur les événements de mer. 2017. Fire of the cargo aboard the container ship CMA CGM Rossini on 15 June 2016, in the port of Colombo. Lorient: BEAmer.

Bruun O, Rasmussen A, Taylor JR. 1979. Cause consequence reporting for accident reduction. The accident anatomy method. Roskilde: Risø National Laboratory. Report Risø-M No. 2206.

[BSU] Federal Bureau of Maritime Causualty Investigation. 2006. Explosion and fire on board CMV PUNJAB SENATOR in Hold No. 6 on 30 May 2005 on the way to Sri Lanka. Federal Bureau of Maritime Causualty Investigation. Hamburg: EMSA.

[BSU] Federal Bureau of Maritime Causualty Investigation. 2014. Fire and explosion on board the MSC Flaminia on 14 july 2012 in the Atlantic and the ensuing events. Federal Bureau of Maritime Causualty Investigation. Hamburg: BSU.

Callesen FG, Blinkenberg-Thrane M. 2017. Container ships - Fire related risk [master's thesis]. Kgs. Lyngby: Technical University of Denmark.

[DCC] The Dow Chemical Company. 2010. Divinylbenzene (DVB) Product Stewardship Manual. Retrieved from http://msdssearch.dow.com/: http://msdssearch.dow.com/PublishedLiteratureDOWCOM/dh_0953/0901b8038 09530fd.pdf?filepath=specialtymonomers/pdfs/noreg/503-\&fromPage=GetDoc

[DMAIB] Danish Maritime Accident Investigation Board. 2016. Marine accident report April 2016 - Caroline Maersk fire in containers on 26 august 2015. Valby: DMAIB.

[EMSA] European Maritime Safety Agency. 2018. European Marine Casualty Information Platform. Retrieved from https://emcipportal.jrc.ec.europa.eu: https://emcipportal.jrc.ec.europa.eu/index.php?id=97

Gissi E. 2009. An introduction to fire simulation with FDS and Smokeview. N/A: Gissi, E.

Hess S, Wohlfahrt-Mehrens M, Wachtler M. 2015. Flammability of Li-Ion Battery Electrolytes: Flash Point and Self-Extinguishing Time Measurements. Journal of The Electrochemical Society, 162 (2) A3084-A3097.

McGrattan K, Hostikka SRM. 2017. Fire dynamics simulator user’s guide.

Murdoch E, Tozer D. 2012. A Master's Guide to Container Securing. 2nd Edition. The Standard \& Lloyd's Register. London: The Standard \& Lloyd's Register. 
[MAREX] The Maritime Executive. 2017. Call for Better Fire-Fighting Systems on Container Ships, 2017-09-19.

Nielsen D. 1975. Use of cause-consequence charts in practical systems analysis. In: Barlow RE, Fussel JB, Singpurwalla ND. Reliability and Fault Tree Analysis. Philadelphia: Society for Industrial and Applied Mathematics; p. 849-880.

[NUREG] U.S. Nuclear Regulatory Commission. 1981. Fault Tree Handbook. NUREG-0492. Washington: NUREG.

[SAMSA] South African Maritime Safety Authority. 2005. Reports on investigations into casualties of MV CSAV Itajai and MV Sea Elegance. www.sjofartsverket.se.

Spouge J. 1999. A Guide to Quantitative Risk Assessment for Offshore Installations. N/A: DNV Technica.

Wolters FC, Pagni PJ, Frost TR, Cuzzillo BR. 2003. Size Constraints On Self Ignition Of Charcoal Briquets. Fire Safety Science 7: 593-604.

UNCTADSTAT. 2017. United Nations Conference on Trade and Development. Statistics 2017, October 24. http://unctadstat.unctad.org/ 
APPENDIX: Fire scenarios categorised by the cargo that initiated the fire

\begin{tabular}{|c|c|c|c|c|c|}
\hline Year & Ship & Cargo & Year & Ship & Cargo \\
\hline 1997 & CONTSHIP FRANCE & $\begin{array}{l}\text { Calcium } \\
\text { Hypochlorite }\end{array}$ & 2006 & $\begin{array}{l}\text { HYUNDAI } \\
\text { FORTUNE }\end{array}$ & $\begin{array}{l}\text { Petroleum-based } \\
\text { cleaning fluid }\end{array}$ \\
\hline 1998 & ACONCAGUA & $\begin{array}{l}\text { Calcium } \\
\text { Hypochlorite }\end{array}$ & 2004 & NYK ARGUS & $\begin{array}{l}\text { PRS-80 \& NA- } \\
125\end{array}$ \\
\hline 1998 & DG HARMONY & $\begin{array}{l}\text { Calcium } \\
\text { Hypochlorite }\end{array}$ & 2004 & CSAV ITAJAI & Thiourea Dioxid \\
\hline 1999 & CMA DJAKARTA & $\begin{array}{l}\text { Calcium } \\
\text { Hypochlorite }\end{array}$ & 2010 & $\begin{array}{l}\text { CHARLOTTE } \\
\text { MAERSK }\end{array}$ & $\begin{array}{l}\text { Methyl ethyl } \\
\text { ketone }\end{array}$ \\
\hline 2002 & $\begin{array}{l}\text { HANJIN } \\
\text { PENSYLVANIA }\end{array}$ & $\begin{array}{l}\text { Calcium } \\
\text { Hypochlorite }\end{array}$ & 2012 & MSC FLAMINIA & Divinylbenzene \\
\hline 2012 & SEA ELEGANCE & $\begin{array}{l}\text { Calcium } \\
\text { Hypochlorite }\end{array}$ & 2013 & $\begin{array}{l}\text { EUGEN } \\
\text { MAERSK }\end{array}$ & Textiles \\
\hline 2012 & $\begin{array}{l}\text { AMSTERDAM } \\
\text { BRIDGE }\end{array}$ & $\begin{array}{l}\text { Calcium } \\
\text { Hypochlorite }\end{array}$ & 2015 & $\begin{array}{l}\text { CAPE } \\
\text { MORETON }\end{array}$ & Sodium hydroxide \\
\hline 2013 & $\begin{array}{l}\text { HANSA } \\
\text { BRANDENBURG }\end{array}$ & $\begin{array}{l}\text { Calcium } \\
\text { Hypochlorite }\end{array}$ & 2015 & PURPLE BEACH & Fertilizer \\
\hline 2014 & HANJIN ATHENS & $\begin{array}{l}\text { Calcium } \\
\text { Hypochlorite }\end{array}$ & 2015 & ALULA & Cardboard bales \\
\hline 2014 & NOTHERN GUARD & $\begin{array}{l}\text { Calcium } \\
\text { Hypochlorite }\end{array}$ & 2006 & YM GREEN & Not uncovered \\
\hline 2015 & $\begin{array}{l}\text { HANJIN GREEN } \\
\text { EARTH }\end{array}$ & $\begin{array}{l}\text { Calcium } \\
\text { Hypochlorite }\end{array}$ & 2009 & $\begin{array}{l}\text { MOL } \\
\text { PROSPERITY }\end{array}$ & Not uncovered \\
\hline 2015 & MAERSK SEOUL & $\begin{array}{l}\text { Calcium } \\
\text { Hypochlorite }\end{array}$ & 2013 & $\begin{array}{l}\text { MAERSK } \\
\text { KAMPALA }\end{array}$ & Not uncovered \\
\hline 2015 & $\begin{array}{l}\text { MAERSK } \\
\text { LONDRINA }\end{array}$ & $\begin{array}{l}\text { Calcium } \\
\text { Hypochlorite }\end{array}$ & 2013 & $\begin{array}{l}\text { CMA CGM } \\
\text { LILAC }\end{array}$ & Not uncovered \\
\hline 1996 & HANSA CLIPPER & Charcoal & 2015 & KAMALA & Not uncovered \\
\hline 1996 & MARLENE S. & Charcoal & 2015 & BARZAN & Not uncovered \\
\hline 1997 & BELLATRIX & Charcoal & 2017 & MSC DANIELA & $\begin{array}{l}\text { Under } \\
\text { investigation }\end{array}$ \\
\hline 2015 & $\begin{array}{l}\text { CAROLINE } \\
\text { MAERSK }\end{array}$ & Charcoal & & & \\
\hline 2015 & MARENO & Charcoal & & & \\
\hline 2015 & MSC KATRINA & Charcoal & & & \\
\hline 2016 & $\begin{array}{l}\text { LUDWIGSHAFEN } \\
\text { EXPRESS }\end{array}$ & Charcoal & & & \\
\hline 2005 & $\begin{array}{l}\text { CMV PUNJAB } \\
\text { SENATOR }\end{array}$ & Batteries & & & \\
\hline 2016 & CMA CGM ROSSINI & Batteries & & & \\
\hline 1998 & $\begin{array}{l}\text { SEA-LAND } \\
\text { MARINER }\end{array}$ & $\begin{array}{l}\text { Pentane \& } \\
\text { isopentane }\end{array}$ & & & \\
\hline
\end{tabular}

